\title{
Serum osteocalcin level is associated with the mortality in Chinese patients with Fibrodysplasia ossificans progressiva aged $\leq 18$ years at diagnosis
}

\author{
Dunmin She, Ran Li, Ping Fang, Guannan Zong, Ying Xue* and Keqin Zhang
}

\begin{abstract}
Background: Fibrodysplasia ossificans progressiva (FOP) is an ultra-rare genetic disorder characterized by extraskeletal heterotopic ossification. It is well recognized that FOP can lead to a devastating condition of disability. However, the mortality rate of FOP patients in China and risk factors for mortality are still largely unclear.

Methods: We conducted a retrospective research on a cohort of 65 cases of FOP patients in China from 2008 to 2018. We reviewed medical records of these FOP patients to retrieve information such as date of birth/death, gender, clinical features, genotypes and biochemical parameters and analyze the correlation of these parameters with the mortality.

Results: 92.3\% (60/65 cases) patients were classic FOP patients, 3.1\% (2/65 cases) were FOP-plus and 4.6\% (3/65 cases) were FOP variants. 9 cases of this cohort were dead during the ten-year period, and the overall mortality rate was 13.8\%. c.617G > A mutation was confirmed in all non-survivors. In FOP patients $\leq 18$ years at diagnosis, nonsurvivors demonstrated significantly lower blood osteocalcin and alkaline phosphatase levels compared with survivors $(P<0.05)$, and spearman correlation and logistic regression analysis indicated that serum osteocalcin and alkaline phosphatase levels were negatively correlated with the mortality. Furthermore, the receiver-operating characteristic curve analysis showed serum osteocalcin had the largest area under the curve of 0.855 among four biochemical parameters, and serum osteocalcin $<65.9 \mathrm{ng} / \mathrm{ml}$ displayed a good capacity to discriminate the nonsurvivors from survivors in FOP patients aged 18 years and younger at diagnosis.
\end{abstract}

Conclusions: Our findings showed that the mortality rate of FOP was $13.8 \%$ in China. Serum OC level was negatively correlated with the mortality in Chinese FOP patients $\leq 18$ years at diagnosis.

Keywords: Fibrodysplasia ossificans progressiva (FOP), Mortality, Risk factors, Osteocalcin

\section{Introduction}

Fibrodysplasia ossificans progressiva (FOP) (Mendelian Inheritance in Man [MIM] \#135100), also known as myositis ossificans progressiva, is a rare genetic disease characterized

*Correspondence: doxy0622@163.com; 13621798084@126.com Department of Endocrinology and Metabolism, Tongji Hospital of Tongji University, Tongji University School of Medicine, No. 389, Xincun Road, Shanghai 200065, China by heterotopic ossification $(\mathrm{HO})$ in anatomical sites and congenital skeletal malformations $[1,2]$ which eventually cause disability. Most patients have congenital malformation of great toes at birth and develop painful inflammatory soft tissue swelling (flare-up) during the first decade of life spontaneously or by trauma [1]. Accumulative painful swelling gradually turns into multiple, and eventually causes joint and bone deformities as well as other disabilities [1].

(c) The Author(s). 2020 Open Access This article is licensed under a Creative Commons Attribution 4.0 International License, which permits use, sharing, adaptation, distribution and reproduction in any medium or format, as long as you give appropriate credit to the original author(s) and the source, provide a link to the Creative Commons licence, and indicate if changes were made. The images or other third party material in this article are included in the article's Creative Commons licence, unless indicated otherwise in a credit line to the material. If material is not included in the article's Creative Commons licence and your intended use is not permitted by statutory regulation or exceeds the permitted use, you will need to obtain permission directly from the copyright holder. To view a copy of this licence, visit http://creativecommons.org/licenses/by/4.0/. The Creative Commons Public Domain Dedication waiver (http://creativecommons.org/publicdomain/zero/1.0/) applies to the data made available in this article, unless otherwise stated in a credit line to the data. 
FOP is an extremely rare disease with prevalence of 1 case in 2 millions in the world [3]. For this reason, patients with FOP are at a high risk of being misdiagnosed and/or underdiagnosed $[4,5]$. FOP is primarily caused by de novo mutation in the Glycine Serine (GS) activation domain of type I activin A receptor (ACVR1), a bone morphogenetic protein (BMP) type I receptor [6, 7]. Approximately 97\% of FOP individuals have ACVR1 (c.617G > A; p.R206H) mutation [6]. Presently, clinical managements for FOP are palliative and symptomatic, which is insufficient to completely prevent long-term complications [8].

Ankylosis of affected joint, which is the most common complication, may result in progressive immobility and lifelong wheelchair-bound [9]. Submandibular swelling can be a life-threatening complication, especially when the patient has difficulty in swallowing [9]. Thoracic insufficiency syndrome usually causes cardiorespiratory failure and pneumonia, which have been reported to be the two most common causes of death in FOP patients [10]. Although much is known about the lethal complications of FOP, few researches reported the mortality of FOP worldwide. By far, there has been only one previous research which described the mortality rate of FOP patients for the first time in the world [10].

It is estimated that there are at least 650 cases of FOP patients in China, the most populous country in the world [11]. However, only a small fraction of Chinese patients with FOP have been reported. Previously, we have reviewed the epidemiology and the research progress of FOP in China [12]. Here, in order to analyze the mortality rate and the risk factors for the mortality, we conducted a retrospective study on a cohort of 65 cases with FOP from 2008 to 2018, and analyzed the medical history, clinical features, genotypes and biochemical parameters of those patients.

\section{Methods \\ Patients}

From December 2008 to December 2018, 65 cases of individuals who were diagnosed as FOP in Tongji Hospital of Tongji University were recruited, consisting of 30 males and 35 females. The diagnosis of FOP was based on the two clinical features [3]: 1) characteristic congenital malformation of the great toes at birth and 2) progressive extraskeletal endochondral ossification. According to clinical classification schemes for FOP [3], 65 individuals were categorized as 60 cases of classic FOP based on classic defining features of FOP, 2 cases of FOP-plus according to atypical features such as cryptorchidism or childhood glaucomain addition to the classic defining features, and 3 patients of FOP variants for their mild malformations of great toes. The diagnosis of FOP in those 65 patients was confirmed based on the clinical manifestations by at least two investigators combined with ACVR1 gene analysis.
Informed consent was obtained from all participants. Our study was approved by the investigational review board of Tongji Hospital of Tongji University.

\section{Methods}

The medical records were reviewed and the following data were collected in FOP patients: date of birth/death, birthplace, gender, personal history, family history, clinical manifestations, physical examinations, and blood biochemical tests. All blood tests were performed at the clinical laboratory of Tongji Hospital of Tongji University. Blood biochemical tests included serum parathyroid hormone level (PTH reference range, $15-65 \mathrm{pg} / \mathrm{mL}$, Roche kit), osteocalcin (OC,10-70 ng/mL, Roche kit), total serum calcium (Ca, 2.2-2.65 mmol/L), alkaline phosphatase (ALP 50-130 U/L), phosphorus (P, 0.81-1.45 mmol/L), erythrocyte sedimentation rate (ESR, 0-20 mm/h), alanine aminotransferase (ALT, 9-50 U/L), aspartate aminotransferase (AST, 15-40 U/L), creatinine (Cr, 44-133 umol/L), and blood uric nitrogen (BUN, 2.9-8.2 mmol/L). According to the previous protocols [3], genomic DNA from blood samples of 50 patients were genotyped for mutations in ACVR1 when their biochemical tests were performed simultaneously. The rest 15 cases were clinically diagnosed without gene analysis. We determined the lifespan by telephone follow-up or outpatient interview in the second half of 2018. All FOP patients were divided into four subgroups according to their prognosis and their ages at diagnosis: non-survivors $\leq 18$ years at diagnosis (group A), survivors $\leq 18$ years at diagnosis (group B), nonsurvivors aged $>18$ years at diagnosis (group C) and survivors aged $>18$ years at diagnosis (group D). All blood tests were performed when they first admitted to our center (which was also the time when they were firstly diagnosed as FOP). None of the FOP patients had taken any medications including glucocorticoid within 1 month before admission to our center.

\section{Statistical analysis}

Statistical package for social sciences (SPSS) 19.0 was used for the statistical analysis. The KolmogorovSmirnov test was used to determine whether the parameters followed a normal distribution. All continuous variables were presented as mean \pm standard deviation. Data were illustrated as medians (interquartile ranges) if not conforming to normal distribution. Comparisons of the means and proportions were performed with independent samples t-test and the chi-square test, respectively. Spearman correlations and logistic regression analysis were performed to explore the risk factors for the mortality of FOP patients. Receiver-operating characteristic (ROC) curves were constructed to estimate the cut-off, sensitivity and specificity of the risk factors which potentially predicted the early death of FOP patients. Tests 
were two-sided and a $P$-value $<0.05$ was considered significant.

\section{Results}

\section{Clinical features of FOP patients}

65 cases of FOP individuals recruited in our study were all Han people from 25 provinces of China. 46.2\% (30/65 cases) were male while $53.8 \%$ (35/65 cases) were female. According to criterion of classification, 92.3\% (60/65 cases) patients were diagnosed as classic FOP patients based on classic defining features of FOP, 3.1\% (2/65 cases) of individuals were FOP-plus since they had classic defining features of FOP and other atypical features such as cryptorchidism or childhood glaucoma, and 4.6\% (3/65 cases) were determined as FOP variants for their mild malformations of great toes. ACVR1 gene analysis was performed in 50 patients and revealed that 48 cases were canonical c.617G > A mutation. Two of FOP variants did not present canonical c.617G > A mutation: one of
FOP variants showed a variant mutation in ACVR1 at c.774G > C (p.R258S), while the rest one had a mutation in ACVR1 at c.1067G > A (p.G356D). (Table 1) In the 65 cases of FOP patients, $84.6 \%$ (55 cases) of FOP patients were initially misdiagnosed before their first visit to our clinic, and approximately $36.9 \%$ of patients (24 cases) had undergone unnecessary biopsies.

\section{Mortality rate of FOP patients}

During the past 10-year period (Dec 2008 to Dec 2018), 9 patients with FOP (3 males and 6 females) were dead while 56 patients ( 27 males and 29 females) were survival. Hence, the total mortality rate was $13.8 \%$ (9/65 cases). The mortality rate in FOP patients aged 18 years and younger at diagnosis was $11.1 \%$ (5/45 cases), whereas it was $20 \%$ ( $4 / 20$ cases) in patients aged over 18 years. All non-survivors were confirmed c.617G $>$ A mutation, and were diagnosed as classic FOP for their congenital malformations of great toes and progressive $\mathrm{HO}$

Table 1 Clinical Features of FOP patients

\begin{tabular}{|c|c|c|c|c|c|c|}
\hline \multirow[b]{2}{*}{ Patient number } & \multirow{2}{*}{$\begin{array}{l}\text { Classic FOP } \\
60 \text { cases }\end{array}$} & \multicolumn{2}{|l|}{ FOP-plus } & \multicolumn{3}{|c|}{ FOP variants } \\
\hline & & 46 & 70 & 7 & 42 & 54 \\
\hline \multicolumn{7}{|l|}{ ACVR1 mutation } \\
\hline -Coden change & $\begin{array}{l}\text { R206H } \\
\text { ( } 45 \text { cases) } \\
\text { or not } \\
\text { complete } \\
\text { (15 cases) }\end{array}$ & $\mathrm{R} 206 \mathrm{H}$ & $\mathrm{R} 206 \mathrm{H}$ & R258S & $\mathrm{R} 206 \mathrm{H}$ & C306D \\
\hline -Nucleotide change (cDNA position) & $\begin{array}{l}\text { c. } 617 G>A \\
\text { ( } 45 \text { cases) } \\
\text { or not } \\
\text { complete } \\
\text { (15 cases) }\end{array}$ & $\begin{array}{l}\text { C. } 617 G> \\
\text { A }\end{array}$ & $\begin{array}{l}\mathrm{C} .617 \mathrm{G}> \\
\mathrm{A}\end{array}$ & $\begin{array}{l}\text { C.744G > } \\
C\end{array}$ & $\begin{array}{l}\text { C.617G > } \\
\text { A }\end{array}$ & $\begin{array}{l}\text { C.1067G > } \\
\text { A }\end{array}$ \\
\hline Gender & M\&F (26/34) & M & M & M & M & $\mathrm{F}$ \\
\hline Age of onset (years) & $0-13$ & 18 & 5 & 6 & 2 & 2.5 \\
\hline \multicolumn{7}{|l|}{ Typical FOP features } \\
\hline -Congenital malformations of Great toes & Y & Y & Y & N & Y & Y \\
\hline -progressive $\mathrm{HO}$ & Y & Y & Y & Y & Y & Y \\
\hline -onset site & $\begin{array}{l}\text { Scalp(45\%); } \\
\text { Neck(20\%); } \\
\text { Back(15\%); } \\
\text { Shoulder } \\
(6.7 \%) \text { Hip } \\
(5 \%) ; \text { Others } \\
(8.3 \%)\end{array}$ & Shoulder & Back & Knee & Scalp & Shoulder \\
\hline \multicolumn{7}{|l|}{ Other typical FOP features } \\
\hline -Thumb malformations & $1.7 \%$ & Y & Y & Y & Y & $\mathrm{N}$ \\
\hline -Knee osteochondromas & $51.7 \%$ & N & $\mathrm{N}$ & Y & $\mathrm{N}$ & N \\
\hline - Scoliosis & $56.7 \%$ & N & N & Y & N & Y \\
\hline -Conductive hearing impairment & $5 \%$ & N & $\mathrm{N}$ & $\mathrm{N}$ & $\mathrm{N}$ & N \\
\hline Atypical FOP features features & $\mathrm{N}$ & Childhood glaucoma & Cryptorchidism & $\begin{array}{l}\text { Minimal } \\
\text { changes } \\
\text { in great } \\
\text { toes }\end{array}$ & $\begin{array}{l}\text { No } \\
\text { changes } \\
\text { in great } \\
\text { toes }\end{array}$ & $\begin{array}{l}\text { Minimal } \\
\text { changes } \\
\text { in great } \\
\text { toes }\end{array}$ \\
\hline
\end{tabular}


(Table 2). The average age at diagnosis (age at first admission to our clinic) of 65 cases was $14.4 \pm 8.8$ years. Among all non-survivors, 5 cases were 18 years and younger at diagnosis, and the rest 4 cases were over 18 years at diagnosis. The average age at diagnosis of nonsurvivors over 18 years and non-survivors aged 18 years and younger were $25.5 \pm 2.4$ years and $11.6 \pm 6.3$ years. The average age of onset (first flare-up or $\mathrm{HO}$ ) of all FOP patients was $4.2 \pm 3.8$ years. There was no significant difference in age at onset between non-survivors over 18 years at diagnosis and non-survivors aged 18 years and younger at diagnosis. The average age at death of all non-survivors was $22.8 \pm 8.9$ years. The age of death in non-survivors over 18 years at diagnosis was significantly older than that in non-survivors aged 18 years and younger at diagnosis $(29.5 \pm 2.9$ years vs $17.4 \pm$ 7.2 years) (Table 3 ).

\section{Risk factors for the mortality of FOP patients}

The clinical and biochemical data of the survival and nonsurvival FOP patients were shown in Table 3. In FOP patients aged 18 years and younger at diagnosis, serum $\mathrm{OC}$ and ALP levels were significantly lower in non-survival patients compared with survivors. Besides, there was no significant difference in gender ratio, age at diagnosis, serum $\mathrm{Ca}, \mathrm{P}, \mathrm{PTH}, \mathrm{ESR}, \mathrm{ALT}, \mathrm{AST}, \mathrm{Cr}$ or BUN at first visit between those two groups. In FOP patients aged over 18 years at diagnosis, there was no significant difference in gender ratio, age at diagnosis, serum $\mathrm{OC}, \mathrm{Ca}, \mathrm{P}, \mathrm{ALP}$, PTH, ESR, ALT, AST, Cr or BUN between survivors and non-survivors (Table 3).

Spearman correlation analysis showed that serum OC, $\mathrm{P}$, ALP were negatively correlated with the mortality in the total FOP patients (supplementary Table 1), whereas serum OC, ALP were negatively associated with the mortality in FOP patients $\leq 18$ years at diagnosis (supplementary Table 2). No correlation between the mortality and the blood biochemical parameters was found in FOP patients $>18$ years at diagnosis (supplementary Table 3 ).

Logistic regression analysis indicated that serum OC level was negatively associated with the mortality in all FOP patients and FOP patients aged 18 years and younger at diagnosis. Further adjustment for age and gender did not change the correlation between serum $\mathrm{OC}$ and the mortality in all FOP patients (OR: $-1.043 ; P=0.030)$ and FOP patients $\leq 18$ years at diagnosis (OR: $-1.224 ; P=$ 0.028). However, in FOP patients aged over 18 years at diagnosis, no association between serum $\mathrm{OC}$ level and the mortality was found.

ROC curves were constructed to evaluate the sensitivity and specificity of the blood biochemical parameters as potential factors to discriminate the non-survivors from survivors of FOP patients aged 18 years and younger at diagnosis. The areas under the ROC curves (AUCs) of

Table 2 Clinical Features of FOP non-survivors

\begin{tabular}{|c|c|c|c|c|c|c|c|c|c|}
\hline Patient number & 1 & 2 & 8 & 21 & 34 & 39 & 41 & 45 & 98 \\
\hline Gender & $\mathrm{F}$ & M & F & M & $\mathrm{F}$ & M & $\mathrm{F}$ & $\mathrm{F}$ & $\mathrm{F}$ \\
\hline Age of onset & 4 & 3 & 2 & 0.1 & 6 & 0.7 & 2.5 & 1 & 6 \\
\hline Age of diagnose (years) & $>18$ & $>18$ & $\leq 18$ & $\leq 18$ & $>18$ & $>18$ & $\leq 18$ & $\leq 18$ & $\leq 18$ \\
\hline Age of death (years) & $>18$ & $>18$ & $>18$ & $\leq 18$ & $>18$ & $>18$ & $>18$ & $\leq 18$ & $>18$ \\
\hline Course of disease (years) & 1 & 6 & 6 & 4 & 6 & 3 & 6 & 6 & 7 \\
\hline \multicolumn{10}{|l|}{ ACVR1 mutation } \\
\hline -Coden change & $\mathrm{R} 206 \mathrm{H}$ & $\mathrm{R} 206 \mathrm{H}$ & $\mathrm{R} 206 \mathrm{H}$ & $\mathrm{R} 206 \mathrm{H}$ & $\mathrm{R} 206 \mathrm{H}$ & $\mathrm{R} 206 \mathrm{H}$ & $\mathrm{R} 206 \mathrm{H}$ & $\mathrm{R} 206 \mathrm{H}$ & R206H \\
\hline -Nucleotide change (cDNA position) & $\begin{array}{l}\text { C.617G }> \\
\text { A }\end{array}$ & $\begin{array}{l}\text { C.617G }> \\
\text { A }\end{array}$ & $\begin{array}{l}\text { C.617G > } \\
A\end{array}$ & $\begin{array}{l}\text { C.617G }> \\
\text { A }\end{array}$ & $\begin{array}{l}\text { C.617G }> \\
A\end{array}$ & $\begin{array}{l}\text { C.617G > } \\
A\end{array}$ & $\begin{array}{l}\text { C.617G > } \\
\text { A }\end{array}$ & $\begin{array}{l}\text { C.617G > } \\
\text { A }\end{array}$ & $\begin{array}{l}\text { C.1067G> } \\
\text { A }\end{array}$ \\
\hline \multicolumn{10}{|l|}{ Typical FOP features } \\
\hline $\begin{array}{l}\text {-Congenital malformations of Great } \\
\text { toes }\end{array}$ & Y & Y & Y & Y & Y & Y & Y & Y & Y \\
\hline -progressive $\mathrm{HO}$ & Y & Y & Y & Y & Y & Y & Y & Y & Y \\
\hline -onset site & Scalp & Neck & Neck & Shoulder & Back & Scalp & Scalp & Scalp & elbow \\
\hline Classification & $\begin{array}{l}\text { Classic } \\
\text { FOP }\end{array}$ & $\begin{array}{l}\text { Classic } \\
\text { FOP }\end{array}$ & $\begin{array}{l}\text { Classic } \\
\text { FOP }\end{array}$ & $\begin{array}{l}\text { Classic } \\
\text { FOP }\end{array}$ & $\begin{array}{l}\text { Classic } \\
\text { FOP }\end{array}$ & $\begin{array}{l}\text { Classic } \\
\text { FOP }\end{array}$ & $\begin{array}{l}\text { Classic } \\
\text { FOP }\end{array}$ & $\begin{array}{l}\text { Classic } \\
\text { FOP }\end{array}$ & Classic FOP \\
\hline \multicolumn{10}{|l|}{ Biochemical tests } \\
\hline$-O C(u / L)$ & 38.1 & 40.7 & 12.7 & 64.7 & 6.58 & 41.5 & 43.9 & 64.8 & 38.0 \\
\hline$-\mathrm{Ca}(\mathrm{mmol} / \mathrm{L})$ & 2.3 & 2.35 & 2.08 & 2.4 & 2.24 & 2.3 & 2.62 & 2.24 & 2.21 \\
\hline$-P(m m o l / L)$ & 1.16 & 1.42 & 1.21 & 1.45 & 0.72 & 1.2 & 1.34 & 1.65 & 1.02 \\
\hline -PTH (pg/ml) & 30.9 & 95.4 & 90.9 & 29 & 53.3 & 86.5 & 37.8 & 50.9 & 78.7 \\
\hline
\end{tabular}


blood biochemical markers were shown in Fig. 1. Among four blood biochemical markers, serum OC had the largest AUC of 0.855 , and serum $\mathrm{OC}<65.9 \mathrm{ng} / \mathrm{mL}$ displayed a sensitivity of $100 \%$ and specificity of $75 \%$ in discriminating the non-survival patients from the survivors in FOP patients $\leq 18$ years at diagnosis. Furthermore, the AUC of serum ALP, P and PTH was 0.837, 0.728 and 0.535 separately. The cut-off points of those four blood biochemical markers as predictors for the mortality in FOP patients aged 18 years and younger at diagnosis were presented in Table 4.

\section{Discussion}

Previous researches of FOP usually focused on clinical features and genetic patterns of FOP patients [1, 13, 14]. However, few study described clinical outcomes in FOP patients. Until recently, only one study of mortality and median lifespan in FOP patients has been reported. That study retrospectively reviewed mortality records of 144 cases from two large registries of FOP patients worldwide, and found the mortality rate was $13.9 \%$ [10]. In our study with Chinese FOP patients, the mortality rate was $13.8 \%$, which was similar to the previous study [10]. However, risk factors for the mortality in FOP patients are still largely unknown.

In our study, we found serum OC level was negatively associated with the mortality in FOP patients, and this correlation only exist in the FOP patients aged 18 years and younger at diagnosis. $\mathrm{OC}$ is a major non-collagenous protein in bone and serves as a biomarker of bone formation mostly. Serum level of OC is significantly correlated with the age [15]. In previous study, serum OC level reaches its peak in girls aged 11-14 years and boys aged 13-15 years. Then, it begins to decrease at the age of 20 years in males and females [16]. It has been reported that the serum OC level is $50-150 \mathrm{ng} / \mathrm{mL}$ in children, whereas it is $12-20 \mathrm{ng} / \mathrm{mL}$ in healthy adults [17]. In our study, the OC level was $87.7 \pm 32.7 \mathrm{ng} / \mathrm{mL}$ in survivors of FOP patients when diagnosed $\leq 18$ years, which was within the reference range of serum $\mathrm{OC}$ level in children according to the previous studies $[16,17]$. However, serum OC level in non-survivors of FOP patients $\leq 18$ years at diagnosis $(48.7 \pm 15.5 \mathrm{ng} / \mathrm{mL})$, which was below the reference range in the previous studies, was significantly lower than that in survivors. Therefore, we speculate that serum OC level might serve as a predictor for the mortality in FOP patients $\leq 18$ years at diagnosis as serum OC levels of nonsurvivors in this age group were below the reference range. However, our conjecture still needs to be confirmed by follow-up studies in the future.

Cardiorespiratory failure from thoracic insufficiency syndrome was a severe complication and a common cause of death in FOP patients [10]. It has been reported that dysregulations of BMP pathway may make an impact on vascular dysfunctions, while overactive BMP signaling in FOP may play a central role in the development of hypoxia-induced pulmonary hypertension [18]. Recent studies have demonstrated serum OC level is closely associated with

Table 3 The baseline characteristics of survivors and non-survivors

\begin{tabular}{|c|c|c|c|c|c|}
\hline \multirow[t]{2}{*}{ FOP patients } & \multicolumn{2}{|l|}{$\leq 18 y$} & \multicolumn{2}{|l|}{$>18 y$} & \multirow[t]{2}{*}{ Total } \\
\hline & $\begin{array}{l}\text { survivors } \\
\text { (group A) }\end{array}$ & non-survivors (group B) & $\begin{array}{l}\text { survivors } \\
\text { (group C) }\end{array}$ & non-survivors (group D) & \\
\hline Cases & $40(88.9 \%)$ & $5(11.1 \%)$ & $16(80 \%)$ & $4(20 \%)$ & 65 \\
\hline Gender ratio (M/F) & $21 / 19$ & $1 / 4$ & $6 / 10$ & $2 / 2$ & $30 / 35$ \\
\hline Age at diagnose (years) & $9.6 \pm 5.0$ & $11.6 \pm 6.3$ & $24.4 \pm 7.1^{* * \Delta \Delta}$ & $25.5 \pm 2.4^{* * \Delta \Delta}$ & $14.4 \pm 8.8$ \\
\hline Age of onset & $3.6 \pm 2.9$ & $2.3 \pm 2.3$ & $4.6 \pm 4.4$ & $3.4 \pm 2.2$ & $4.2 \pm 3.9$ \\
\hline Age at death (years) & - & $17.4 \pm 7.2$ & - & $29.5 \pm 2.9^{\Delta \Delta}$ & $22.8 \pm 8.9$ \\
\hline OC (ng/mL) & $87.7 \pm 32.7$ & $48.7 \pm 15.5^{* *}$ & $34.7 \pm 19.8^{* *}$ & $26.8 \pm 16.1^{* *}$ & $67.9 \pm 37.8$ \\
\hline $\mathrm{Ca}(\mathrm{mmol} / \mathrm{L})$ & $2.32 \pm 0.2$ & $2.34 \pm 0.07$ & $2.32 \pm 0.08$ & $2.24 \pm 0.05$ & $2.32 \pm 0.15$ \\
\hline $\mathrm{P}(\mathrm{mmol} / \mathrm{L})$ & $1.58 \pm 0.25$ & $1.42 \pm 0.15$ & $1.23 \pm 0.3^{* *}$ & $1.02 \pm 0.21^{* * \Delta}$ & $1.45 \pm 0.31$ \\
\hline PTH (pg/mL) & $63.3 \pm 487.4$ & $53.2 \pm 25.9$ & $81.5 \pm 37.7$ & $71.9 \pm 14.3$ & $67.5 \pm 42.8$ \\
\hline ALP (IU/L) & $244.0 \pm 121.1$ & $128.2 \pm 85.0^{*}$ & $121.9 \pm 78.6^{* *}$ & $82.2 \pm 24.9^{*}$ & $192.3 \pm 121.9$ \\
\hline ESR (mm/hr) & $7.9 \pm 5.2$ & $9.4 \pm 8.7$ & $10.2 \pm 9.2$ & $9.25 \pm 5.6$ & $8.6 \pm 7.8$ \\
\hline $\operatorname{ALT}(U / L)$ & $14.9 \pm 7.2$ & $10.6 \pm 3.4$ & $15.0 \pm 10.6$ & $16.7 \pm 13.2$ & $14.6 \pm 8.0$ \\
\hline AST (U/L) & $24.6 \pm 9.7$ & $23.1 \pm 6.0$ & $25.3 \pm 10.9$ & $19.57 \pm 12.7$ & $24.3 \pm 13.3$ \\
\hline Cr (umol/L) & $38.0 \pm 14.3$ & $31.0 \pm 5.2$ & $46.8 \pm 14.0$ & $43.7 \pm 11.3$ & $39.4 \pm 14.0$ \\
\hline BUN (mmol/L) & $2.0-5.8$ & $1.7-7.2$ & $2.9-6.3$ & $2.2-5.3$ & $1.7-7.2$ \\
\hline
\end{tabular}

Compared with group $\mathrm{A},{ }^{*} \mathrm{P}<0.05,{ }^{* *} \mathrm{P}<0.01$; Compared with group $\mathrm{B},{ }^{\Delta} \mathrm{P}<0.05,{ }^{\Delta \triangle} \mathrm{P}<0.01$;

$O C$ osteocalcin, $C a$ total serum calcium, $P$ phosphorus, $P T H$ parathyroid hormone, $A L P$ alkaline phosphatase, ESR erythrocyte sedimentation rate, $C R P C$-reactive protein, ALT alanine aminotransferase, AST aspartate aminotransferase, $C r$ creatinine, BUN blood urea nitrogen 
OC

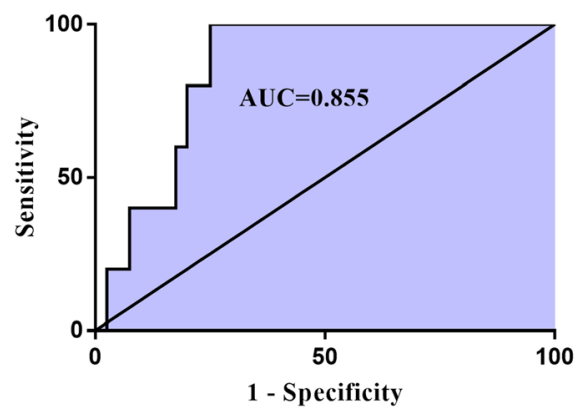

ALP

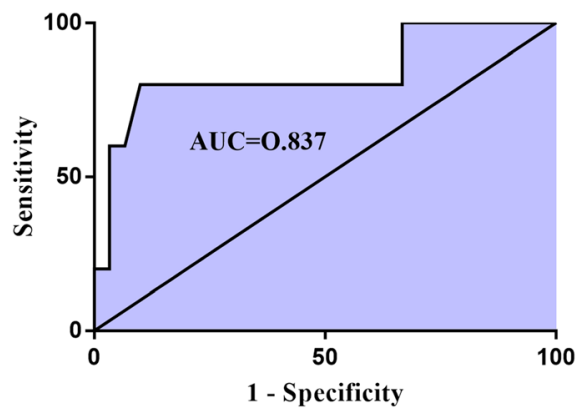

$\mathbf{P}$

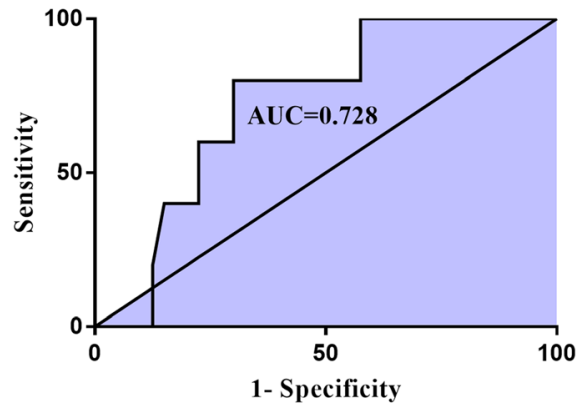

PTH

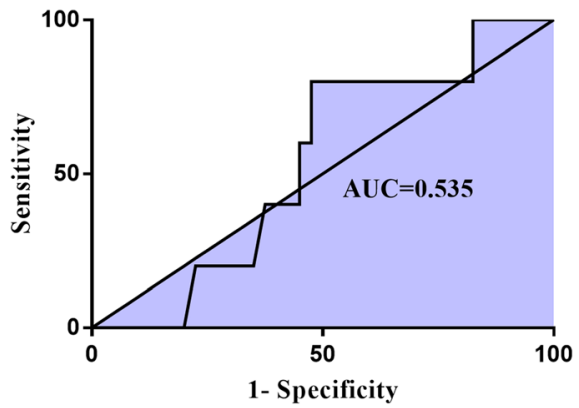

Fig. 1 Receiver-operating characteristic (ROC) curves for the ability of serum OC, $P, A L P$ and PTH to discriminating the non-survivors from the survivors in FOP patients with age $\leq 18 \mathrm{y}$. Cl, confidence interval. The area under the ROC curve (AUC) $=0.855$ for OC, $P=0.010,95 \% \mathrm{Cl} 0.739-0.971$; $A U C=0.728$ for $P, P=0.100,95 \% C l 0.547-0.908$; $A U C=0.837$ for $A L P, P=0.017,95 \% C l$ l $0.605-1.068$; AUC $=0.535$ for $P$ TH $, P=0.800,95 \% C l 0.320-$ 0.750. OC: osteocalcin; P: phosphorus; ALP: alkaline phosphatase; PTH: parathyroid hormone

cardiovascular disease. Zhang et al. [19] found that lower serum OC levels were associated with a higher risk of major adverse cardiovascular events in a retrospective cohort study of Chinese subjects. A longitudinal analysis demonstrated that men with low OC levels exhibit increased allcause mortality and cardiovascular disease related mortality [20]. In our study, we found that serum OC level was negatively correlated with the mortality in FOP patients $\leq 18$ years at diagnosis. Therefore, we speculate that serum OC level was negatively associated with the mortality in FOP patients aged 18 years and younger at diagnosis might due to its relationship with dysfunction of cardiopulmonary system. However, the relationship between serum OC level and the cause of death in FOP patients still needs to be clarified in the future study.
Bone transformation markers including $\mathrm{OC}$ are highly dependent on gender, age and pubertal stage $[21,22]$. In our analysis, after adjusting for age and gender, serum OC level was negatively associated with the mortality in all FOP patients and FOP patients aged 18 years and younger at diagnosis. We did not analyze the effect of pubertal stage on biomarkers due to small size of samples. In addition, since the identification of the severity of FOP is still unclear, we are not sure if the severity of FOP has an effect on serum biomarkers.

Our research has several limitations. Firstly, 65 of FOP patients were recruited in our study, which only represent $10 \%$ of all FOP patients in China [11]. Secondly, it is a retrospective study without long-term follow-up. Serum biochemical parameters of FOP patients may fluctuate

Table 4 Area under the Curve and related parameters

\begin{tabular}{|c|c|c|c|c|c|c|}
\hline & $A \cup C$ & Cut-off point & Sensitivity & Specificity & $P$-value & $95 \% \mathrm{Cl}$ \\
\hline OC & 0.855 & $<65.9 \mathrm{ng} / \mathrm{mL}$ & $100 \%$ & $75 \%$ & $0.010^{*}$ & $0.739-0.971$ \\
\hline$P$ & 0.728 & $<1.47 \mathrm{mmol} / \mathrm{L}$ & $80 \%$ & $70 \%$ & 0.100 & $0.547-0.908$ \\
\hline ALP & 0.837 & $<122.9 \mathrm{IU} / \mathrm{L}$ & $80 \%$ & $90 \%$ & $0.017^{*}$ & $0.605-1.068$ \\
\hline PTH & 0.535 & $<55.7 \mathrm{pg} / \mathrm{mL}$ & $80 \%$ & $52.5 \%$ & 0.800 & $0.320-0.750$ \\
\hline
\end{tabular}

${ }^{*} P<0.05$

$O C$ osteocalcin, $P$ phosphorus, ALP alkaline phosphatase, $P T H$ parathyroid hormone 
dynamically considering the long-lasting process of this disease. Thus, further follow-up study is needed to confirm our result in a larger cohort of patients.

\section{Conclusions}

In summary, our study described the mortality rate and related risk factors for the mortality of FOP patients in China for the first time. We found that the mortality rate of FOP was $13.8 \%$ and serum OC level was negatively correlated with the mortality in Chinese FOP patients $\leq 18$ years at diagnosis. Our study could be valuable in predicting lethal outcome of FOP patients aged 18 years and younger at diagnosis, allowing interventions to be conducted most effectively to reduce the associated mortality.

\section{Supplementary information}

Supplementary information accompanies this paper at https://doi.org/10. 1186/s12891-020-3170-3

Additional file 1: Supplementary Table 1. Spearman correlations between parameters and mortality in FOP patients. Supplementary

Table 2. Spearman correlations between parameters and mortality in FOP patients with age $\leq 18$ years. Supplementary Table 3. Spearman's correlations between parameters and mortality in FOP patients with age $>18$ years.

\section{Abbreviations}

ACVR1: Type I activin A receptor; ALP: Alkaline phosphatase; ALT: Alanine aminotransferase; AST: Aspartate aminotransferase; AUCs: Areas under the ROC curves; BMP: Bone morphogenetic protein; BUN: Blood uric nitrogen; Ca: Calcium; Cr: Creatinine; ESR: Erythrocyte sedimentation rate; FOP: Fibrodysplasia ossificans progressiva; GS: Glycine Serine; HO: Heterotopic ossification; OC: Osteocalcin; P: Phosphorus; PTH: Parathyroid hormone; ROC: Receiver-operating characteristic; SPSS: Statistical package for social sciences

\section{Acknowledgements}

Not applicable.

\section{Authors' contribution}

Conceived and designed the research, wrote and revised the manuscript: YX, KQZ and DMS. Collected the data: DMS, RL, PF and GNZ. Analyzed the data:

DMS, RL, PF and GNZ. All authors approved the final manuscript as submitted and agreed to be accountable for all aspects of the work.

\section{Funding}

This study was supported by the National Natural Science Foundation of China (Grant No. 81400834, 81670805 and 81974105), Novo Nordisk China Diabetes Young Scientific Talent Research Funding, the Science and Technology Innovation Program of Shanghai STCSM (Grant No.164 11954700) and Shanghai Pujiang Program. YX was supported by the National Natural Science Foundation of China (Grant No. 81400834 and 81974105), Novo Nordisk China Diabetes Young Scientific Talent Research Funding and Shanghai Pujiang Program. KQZ was supported by the National Natural Science Foundation of China (Grant No. 81670805) and the Science and Technology Innovation Program of Shanghai STCSM (Grant No.16411954700). All grants provided assistance in patients follow-up and data collection. YX and KQZ helped in writing the manuscript, such as organization of the structure and modification of the text.

\section{Availability of data and materials}

The datasets used and analyzed during the current study are available from the corresponding author on reasonable request.

\section{Ethics approval and consent to participate}

All procedures performed in studies involving human participants were in accordance with the 1964 Helsinki declaration and its later amendments or comparable ethical standards. Ethical approval for the study was obtained from the Ethical Committee of Tongji Hospital of Tongji University. Informed consent was obtained from each individual participant (or their parent or guardian in the case of children under 16) included in the study.

\section{Consent for publication}

Not applicable.

\section{Competing interests}

The authors declare that they have no competing interests.

Received: 2 October 2019 Accepted: 26 February 2020

Published online: 31 July 2020

\section{References}

1. Pignolo RJ, Shore EM, Kaplan FS. Fibrodysplasia ossificans progressiva: clinical and genetic aspects. Orphanet J Rare Dis. 2011;6(80):1750-172. https://doi.org/10.1186/1750-1172-6-80.

2. Kaplan FS, Le Merrer M, Glaser DL, et al. Fibrodysplasia ossificans progressiva. Best Pract Res Clin Rheumatol. 2008;22(1):191-205. https://doi. org/10.1016/j.berh.2007.11.007

3. Kaplan FS, Xu M, Seemann P, et al. Classic and atypical fibrodysplasia ossificans progressiva (FOP) phenotypes are caused by mutations in the bone morphogenetic protein (BMP) type I receptor ACVR1. Hum Mutat. 2009;30(3):379-90. https://doi.org/10.1002/humu.20868.

4. Solomon D, Wakjira I, Hailu D, et al. Fibroplasia Ossificans Progressiva: a case report of a rare disease entity. Ethiop J Health Sci. 2018;28(4):513-6. https:// doi.org/10.4314/ejhs.v28i4.17.

5. Kitterman JA, Kantanie S, Rocke DM, et al. latrogenic harm caused by diagnostic errors in fibrodysplasia ossificans progressiva. Pediatrics. 2005; 116(5):e654-61. https://doi.org/10.1542/peds.2005-0469.

6. Kaplan FS, Pignolo RJ, Shore EM. The FOP metamorphogene encodes a novel type I receptor that dysregulates BMP signaling. Cytokine Growth Factor Rev. 2009;20(5-6):399-407. https://doi.org/10.1016/j.cytogfr.2009.10. 006.

7. Shore EM, Xu M, Feldman GJ, et al. A recurrent mutation in the BMP type I receptor ACVR1 causes inherited and sporadic fibrodysplasia ossificans progressiva. Nat Genet. 2006;38(5):525-7. https://doi.org/10.1038/ng1783.

8. Wentworth KL, Masharani U, Hsiao EC. Therapeutic advances for blocking heterotopic ossification in fibrodysplasia ossificans progressiva. $\mathrm{Br} J \mathrm{Clin}$ Pharmacol. 2019:85(6). https://doi.org/10.1111/bcp.13823.

9. Pignolo RJ, Shore EM, Kaplan FS. Fibrodysplasia ossificans progressiva: diagnosis, management, and therapeutic horizons. Pediatr Endocrinol Rev. 2013;10(2):437-48

10. Kaplan FS, Zasloff MA, Kitterman JA, et al. Early mortality and cardiorespiratory failure in patients with fibrodysplasia ossificans progressiva. J Bone Joint Surg Am. 2010;92(3):686-91. https://doi.org/10.2106/JBJS.I. 00705.

11. Zhang W, Zhang $K$, Song $L$, et al. The phenotype and genotype of fibrodysplasia ossificans progressiva in China: a report of 72 cases. Bone. 2013;57(2):386-91. https://doi.org/10.1016/j.bone.2013.09.002.

12. She D, Zhang K. Fibrodysplasia ossificans progressiva in China. Bone. 2018, 109:101-3. https://doi.org/10.1016/j.bone.2017.11.016.

13. Jiao $S$, Zhang $Y, M a ~ W$, et al. FOP in China and Japan: an overview from domestic literatures. Am J Med Genet A. 2013;161A(4):892-3. https://doi. org/10.1002/ajmg.a.35771.

14. Morales-Piga A, Bachiller-Corral J, Trujillo-Tiebas MJ, et al. Fibrodysplasia ossificans progressiva in Spain: epidemiological, clinical, and genetic aspects. Bone. 2012;51(4):748-55. https://doi.org/10.1016/j.bone.2012.07.002.

15. Civitelli R, Armamento-Villareal R, Napoli N. Bone turnover markers: understanding their value in clinical trials and clinical practice. Osteoporos Int. 2009;20(6):843-51. https://doi.org/10.1007/s00198-009-0838-9.

16. Bayer M. Reference values of osteocalcin and procollagen type I Npropeptide plasma levels in a healthy central European population aged 018 years. Osteoporos Int. 2014;25(2):729-36. https://doi.org/10.1007/s00198013-2485-4

17. Luo Y, Ma X, Hao Y, et al. Relationship between serum osteocalcin level and carotid intima-media thickness in a metabolically healthy Chinese 
population. Cardiovasc Diabetol. 2015;14:82. https://doi.org/10.1186/s12933015-0245-9.

18. Fiori JL, Billings PC, de la Peña $L S$, et al. Dysregulation of the BMP-p38 MAPK signaling pathway in cells from patients with fibrodysplasia ossificans progressiva (FOP). J Bone Miner Res. 2006;21(6):902-9. https://doi.org/10. 1359/jbmr.060215.

19. Zhang $X$, Shen $Y, X u Y$, et al. Association of serum osteocalcin levels with major adverse cardiovascular events: a 4.4-year retrospective cohort study. Clin Exp Pharmacol Physiol. 2018;45:3-9. https://doi.org/10.1111/1440-1681. 12853.

20. Yeap BB, Chubb SA, Flicker $L$, et al. Associations of total osteocalcin with allcause and cardiovascular mortality in older men. The health in men study. Osteoporos Int. 2012;23(2):599-606. https://doi.org/10.1007/s00198-0111586-1.

21. Rauchenzauner M, Schmid A, Heinz-Erian P, et al. Sex- and age-specific reference curves for serum markers of bone turnover in healthy children from 2 months to 18 years. J Clin Endocrinol Metab. 2007;92(2):443-9. https://doi.org/10.1210/jc.2006-1706

22. Gundberg CM, Looker AC, Nieman SD, et al. Patterns of osteocalcin and bone specific alkaline phosphatase by age, gender, and race or ethnicity Bone. 2002;31(6):703-8. https://doi.org/10.1016/s8756-3282(02)00902-x.

\section{Publisher's Note}

Springer Nature remains neutral with regard to jurisdictional claims in published maps and institutional affiliations.

Ready to submit your research? Choose BMC and benefit from:

- fast, convenient online submission

- thorough peer review by experienced researchers in your field

- rapid publication on acceptance

- support for research data, including large and complex data types

- gold Open Access which fosters wider collaboration and increased citations

- maximum visibility for your research: over $100 \mathrm{M}$ website views per year

At $\mathrm{BMC}$, research is always in progress.

Learn more biomedcentral.com/submissions 